\title{
Helping Hand: inclusão social e reintegração através da informação.
}

\author{
Aline Weber ${ }^{1}$, Ingrid Baggio Smalti ${ }^{1}$, Luana Lazzarotto Bianchi ${ }^{1}$, Monique \\ Machado Invernizzi ${ }^{1}$, Tiago Martins da Silva Goulart ${ }^{1}$
}

${ }^{1}$ Instituto Federal de Educação, Ciência e Tecnologia do Rio Grande do Sul - Avenida Osvaldo Aranha, 540 | Bairro Juventude da Enologia | CEP: 95700-000 | Bento

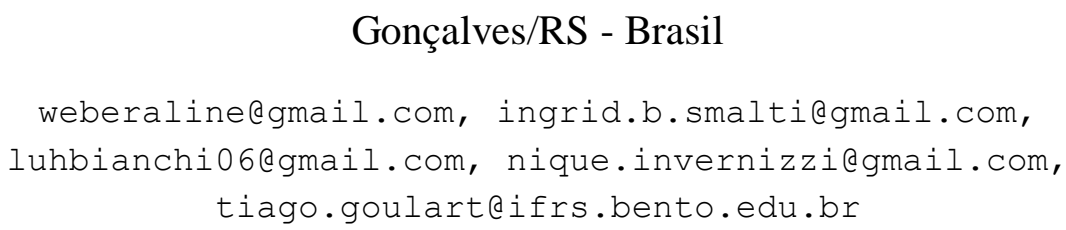

\begin{abstract}
The present paper aims to describe the process of conception, creation and development of the project Helping Hand, proposed to facilitate the information access to immigrants and refugees established in Brazil. Hereby are also available informations about the immigration situation in the mentioned country, gathered during the elaboration of the project, so that thus it is set up a panorama of the real needs of Helping Hand target public and its features.
\end{abstract}

Resumo. O presente artigo tem como objetivo descrever o processo de concepção, de criação e de desenvolvimento do projeto Helping Hand, cuja finalidade é facilitar o acesso à informação para imigrantes $e$ refugiados residentes no Brasil. Neste mesmo texto também serão disponibilizadas informações sobre a situação imigratória do país anteriormente citado, colhidas durante a elaboração do trabalho, para que assim se estabeleça um panorama das reais necessidades e carências do público alvo do Helping Hand e suas funcionalidades.

\section{Cenário de Uso}

O software Helping Hand ${ }^{1}$ tem enfoque voltado a refugiados e a imigrantes residentes no Brasil e a toda comunidade que tem interesse pela temática de imigrações contemporâneas. Propõe-se através deste, o mapeamento de diversas organizações, espalhadas em todo território nacional, que fornecem apoio a esses estrangeiros. Alguns exemplos são instituições de ensino, entidades beneficentes, órgãos governamentais,

1 URL: www.helpinghandapp.com.br e endereço para download na Playstore: https://play.google.com/store/apps/details?id=helpinghandapp.com.br 


\section{CBIE-LACLO 2015}

Anais dos Workshops do IV Congresso Brasileiro de Informática na Educação (CBIE 2015)

entre outros. O sistema está desenvolvido em cinco linguagens: português, inglês, espanhol, francês e árabe. Tal recurso se faz necessário visto que o idioma é uma barreira para a maior parte do público alvo e o grande objetivo da projeto é fornecer informações para que eles sejam direcionados a instituições que possam auxiliá-los na integração à comunidade, propondo acesso aos dados de maneira facilitada.

\subsection{O problema identificado}

Nos últimos anos, temáticas envolvendo refugiados, imigrantes e deslocamentos populacionais têm sido temas frequentes em debates; em vista disso dois questionamentos foram levantados: quais medidas estão sendo, de fato, tomadas para tornar a vida desses estrangeiros melhor? Como nós poderíamos ajudá-los de alguma forma?

A partir destas indagações, com a constatação de que não existe nenhuma ferramenta de auxílio a esses estrangeiros em nosso país, e com um projeto de pesquisa anterior ao desenvolvimento do aplicativo e do website, decidiu-se seguir este trajeto, buscando direcionar este grupo que passa por dificuldades ao caminho de entidades que possam ajudar a melhorar suas condições de vida, através dos serviços específicos oferecidos por cada uma.

Assim, estabeleceram-se contatos com as mais diversas instituições de várias partes do Brasil, para poder verificar as maiores carências e necessidades apontadas, e dessa maneira foram criadas as funcionalidades do aplicativo.

\subsection{Crescente número de pedidos de refúgio}

Atualmente o Brasil é o país que mais acolhe pedidos de refúgio em toda América Latina (2.320 só no ano de 2014) ${ }^{2}$. Para ter-se uma visão mais aprofundada, nos últimos quatro anos, o número de requerimentos de refúgio somente de sírios aumentou em torno de $800 \%{ }^{3}$. Observa-se que o Brasil tem uma política migratória extremamente amigável, o que indica que o público alvo deste sistema só tende a crescer. António Guterres, do Alto Comissário das Nações Unidas para os Refugiados, declarou durante sua visita ao Brasil, em novembro de 2005, “O Brasil é um país de asilo e exemplo de comportamento generoso e solidário" (Figura 1).

\footnotetext{
${ }^{2}$ Dados retirados do website: http://tvbrasil.ebc.com.br/reporterbrasil/bloco/brasil-e-o-pais-querecebe-mais-refugiados-na-america-latina-e-caribe. Acesso em 15 de abril de 2015.

${ }^{3}$ Informação retirada do website: http://www.vermelho.org.br/noticia/260591-10. Acesso em 14 de abril de 2015.
} 
CBIE-LACLO 2015

Anais dos Workshops do IV Congresso Brasileiro de Informática na Educação (CBIE 2015)

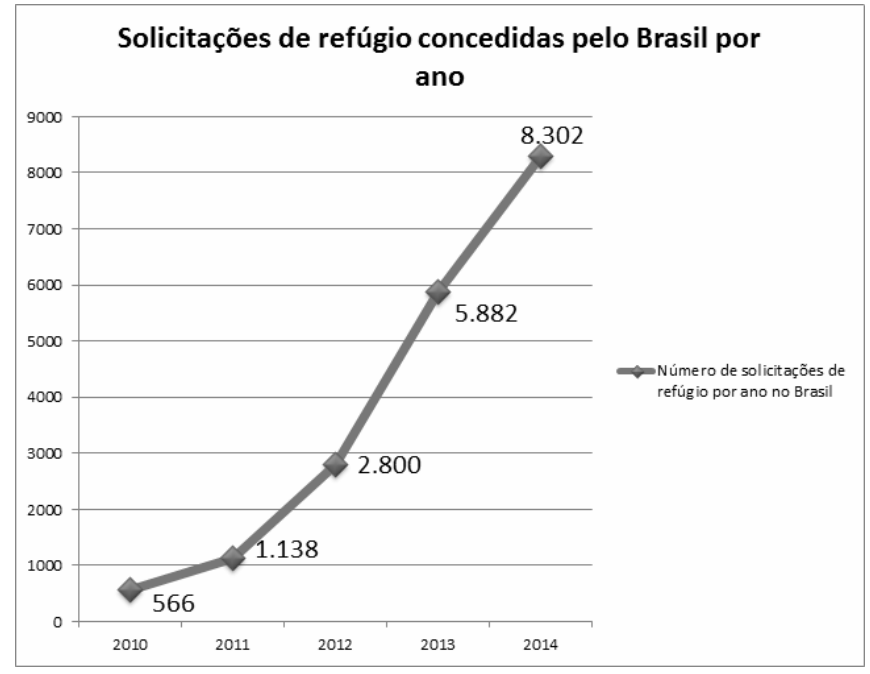

Figura 1. Número de solicitações de refúgio concedidas no Brasil pelo Comitê Nacional para os Refugiados (CONARE) por ano.

\section{Metodologia}

Para iniciar o desenvolvimento da ferramenta, buscou-se o auxílio de diversas instituições com tradição no atendimento ao refugiado e ao imigrante. Através destas entidades, foi possível estabelecer quais são as principais necessidades e problemas enfrentados pelos estrangeiros. A partir disso, debateram-se as prováveis soluções para eles. Em um segundo momento, recorreu-se à ajuda de pessoas que passaram por dificuldades, e, assim, observou-se o problema com a ótica dos próprios imigrantes e refugiados.

Posteriormente às entrevistas, analisaram-se dados oficiais junto a órgãos da Organização das Nações Unidas (ONU), como a Alto Comissário das Nações Unidas para os Refugiados (ACNUR), e também junto ao Comitê Nacional para os Refugiados (CONARE), o órgão brasileiro responsável pela concessão do status de refugiado ao imigrante.

Essa etapa inicial de pesquisas e entrevistas durou em torno de três meses e foi essencial para a análise do sistema como um todo e foi o período em que decidiu-se as principais funcionalidades e idiomas implementados tanto no aplicativo quando no website.

\section{Referencial teórico}

Os elementos fundamentais que compõem o projeto Helping Hand são, do ponto de vista técnico-profissional, as ideias de aplicativo e de website, ambas relacionadas à noção de software; e do ponto de vista social a identificação das migrações humanas 


\section{CBIE-LACLO 2015}

Anais dos Workshops do IV Congresso Brasileiro de Informática na Educação (CBIE 2015)

como fenômeno histórico que tem como sujeitos as figuras do imigrante e/ou do refugiado.

Nesse sentido, entende-se por Software, é todo programa de computador (desktop, smartphone, notebook, entre outros) e sua documentação associada (SOMMERVILLE, 2007), e segundo Roger S. Pressman, "software consiste em: (1) instruções que, quando executadas, fornecem características, funções e desempenhos desejados; (2) estruturas de dados que possibilitam aos programas manipular informações adequadamente; e (3) informação descritiva, tanto na forma impressa com na virtual, descrevendo a operação e uso dos programas".

Um website encaixa-se na categoria de "Aplicações para a Web", dentre as existentes para software. Este grupo abrange uma vasta gama de aplicações, podendo ser, desde sua forma mais simples, um conjunto de arquivos hipertexto interligados, até sofisticados ambientes computacionais que chegam a incorporar-se a bancos de dados corporativos e aplicações comerciais.

Um aplicativo para dispositivos móveis (Figura 2), pertence a categoria da "Computação mundial aberta", que consiste em aplicações que permitem que dispositivos móveis, computadores pessoais e sistemas corporativos se comuniquem através de extensas redes.

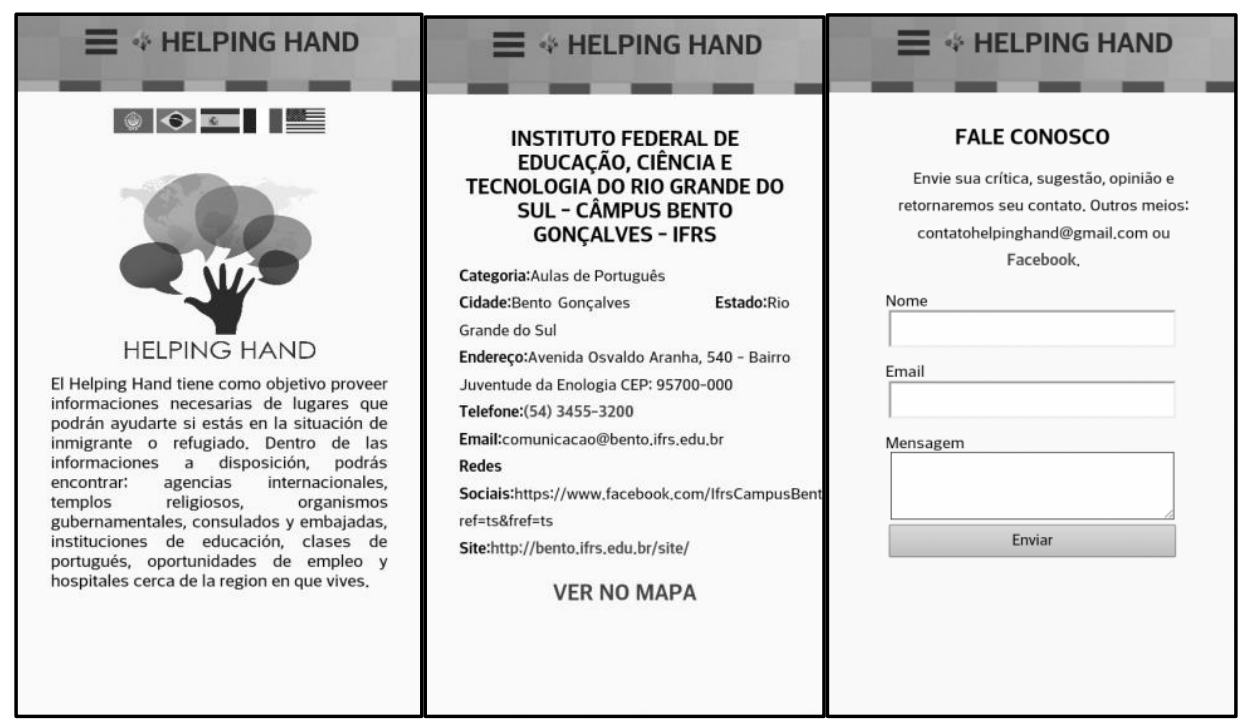

Figura 2. Capturas de tela do aplicativo.

\section{Desenvolvimento}

Após a etapa inicial de concepção e de análise do projeto, iniciou-se o desenvolvimento do website, que teve layout formulado com base no logotipo, suas cores e fontes. $\mathrm{O}$ logo, por sua vez, foi idealizado pensando na internacionalidade e na abrangência linguística do Helping Hand. Tais elementos estão presentes na representação do mapa 
mundi, e o mesmo é sobreposto por alguns ícones que representam a fala e a variedade de idiomas em que o sistema está disponível. Finalmente, o último elemento teve uma retratação literal, ou seja, uma "Mão" (Hand). No site foram utilizadas as seguintes linguagens: PHP, HTML5, CSS3, JavaScript e a biblioteca jQuery.

Com a conclusão desta etapa, passou-se a conversão para o aplicativo. Foi usada a ferramenta PhoneGap, um framework grátis e de código aberto desenvolvido pela Adobe, que realiza a conversão de páginas HTML e JavaScript para o equivalente em um aplicativo.

\section{Acessibilidade}

Com o objetivo de melhorar a acessibilidade de ambos os sistemas, foi de extrema necessidade disponibilizar tanto o website quanto o aplicativo em outros idiomas. Para tanto, foi realizada uma pesquisa junto às instituições de acolhimento de imigrantes e refugiados em diversos estados brasileiros e levantaram-se as prioridades linguísticas do nosso sistema. Assim, estabeleceram-se o árabe, espanhol, francês, inglês e o português como prioridades, já que são os idiomas falados pela maior parte dos estrangeiros que se estabelecem no Brasil. Dentre os refugiados, por exemplo, 2.586 são falantes do árabe, 979 do espanhol, 799 do francês e 395 do inglês, este último sendo também o idioma internacional, que oportuniza a comunicação com todos ${ }^{4}$.

\section{Acesso à informação de forma simples e clara}

Uma das grandes vantagens do sistema é o fato de que todos os dados nele contidos possuem um acesso facilitado através de meios de busca autoexplicativos. Para acessar as informações sobre endereços úteis basta acessar a página "Entidade" e realizar a busca preenchendo os campos "Estado", "Cidade" e "Categoria" da forma que desejar (Figura 3). O breve formulário encontra-se nos cinco idiomas acima citados, tornandose acessível a todos. Já para visualizar todos estes endereços em um mapa, basta clicar na guia "Mapa". Nesta página, um guia cartográfico é disposto com as legendas dos locais nele marcados.

\footnotetext{
${ }^{4}$ Dados retirados do website: http://www.conjur.com.br/2015-jan-13/brasil-acolheu-2320-refugiadosestrangeiros-2014
} 
CBIE-LACLO 2015

Anais dos Workshops do IV Congresso Brasileiro de Informática na Educação (CBIE 2015)

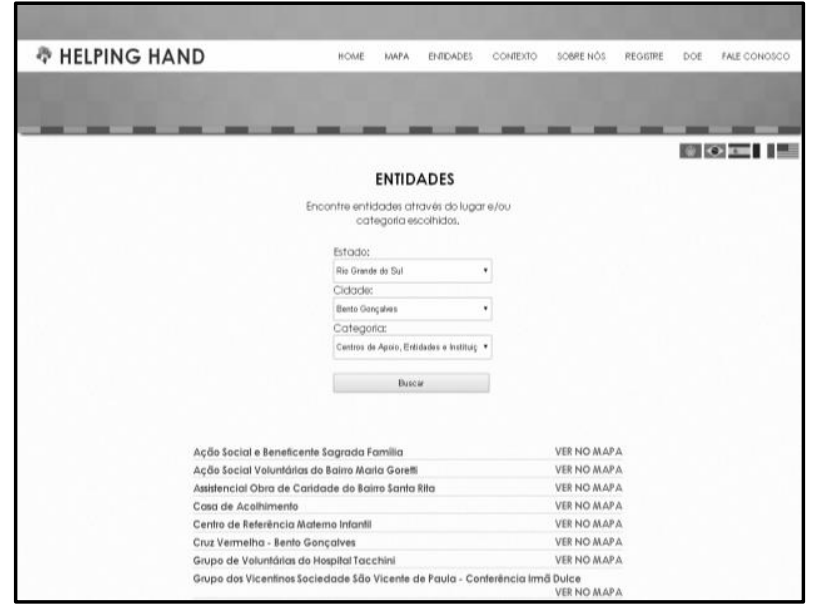

Figura 3. Imagem da tela do sistema destinada à busca de entidades no website.

\section{Ferramenta de engajamento social e conscientização}

Além de ser uma poderosa ferramenta de disseminação de informações, é também um instrumento de conscientização social, uma vez que através do Helping Hand a comunidade como um todo pode tomar conhecimento sobre a temática que engloba imigrações e refúgio. Não obstante, também disponibiliza-se uma guia denominada "Doe" (Figura 4), onde é possível realizar doações que serão repassadas para entidades beneficentes ou então convertidas em alimentos e em artigos de inverno que serão distribuídos para os estrangeiros em vulnerabilidade social.

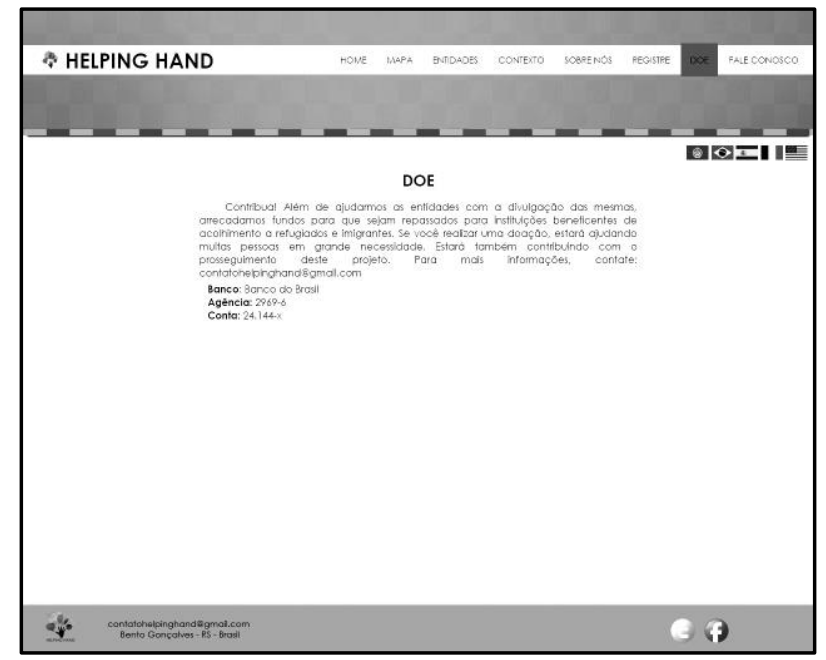

Figura 4. Imagem da tela do sistema destinada à busca de entidades.

\section{8 . Aplicação da ferramenta no ambiente escolar}




\section{CBIE-LACLO 2015}

Anais dos Workshops do IV Congresso Brasileiro de Informática na Educação (CBIE 2015)

Tanto o website quanto o aplicativo têm a possibilidade de aplicação em sala de aula, uma vez que demonstra ser uma ferramenta objetivadora de debates acerta da temática migratória, que é tão presente na atualidade. Através do Helping Hand, é possível acessar uma guia denominada "Contexto", aonde o usuário encontra informações sobre o que é refúgio, o que caracteriza uma pessoa como refugiado e como imigrantes, além de expor a situação vivenciada por esses grupos.

Além disso, através da busca por entidades, viabiliza-se entrar em contato com instituições de pesquisa sobre deslocamentos populacionais e entidades de apoio aos imigrantes e aos refugiados, permitindo que o meio educacional adentre à esfera prática da situação apresentada.

\section{Considerações finais}

Apesar de ser uma ferramenta bem recente, com apenas três meses desde a data do seu lançamento, a receptividade do público foi grande, superando as expectativas da equipe. Atualmente o aplicativo conta com 193 downloads, além disso os usuários, até o momento, avaliaram o mesmo com a nota máxima na Playstore. No website o acesso é ainda mais intenso: obtemos 1.090 sessões somente no mês de agosto.

Conta-se também com a participação de dezenas de indivíduos que contribuem não apenas para a ampliação do projeto, mas também para a realização de doação de alimentos, efetuadas junto a alguma entidade de acolhimento ao imigrante e ao refugiado. Além disso o Helping Hand não apenas está servindo para ajudar diretamente imigrantes e refugiados, mas mostra-se uma ferramenta que permite levantar o debate sobre deslocamentos populacionais no meio estudantil, tanto na academia quanto na escola.

O banco de dados do Helping Hand continua a ser atualizado semanalmente, com a atualização de informações, como a inserção de novos endereços ou alterações sugeridas pelos usuários.

\section{Referências}

ACNUR. "Coletânea de Instrumentos de Proteção Nacional e Internacional de Refugiados e Apátridas",http://www.migrante.org.br/migrante/images/arquivos/lei947-97-coletane a-ins trumentos.pdf.

ACNUR. (2014) "Refúgio no Brasil", http://www.acnur.org/t3/fileadmin/Documen tos/portugues/Estatisticas/Refugio_no_Brasil_2010_2014.pdf?view=1. 
CBIE-LACLO 2015

Anais dos Workshops do IV Congresso Brasileiro de Informática na Educação (CBIE 2015)

Estarque, M. and Gomes, K. (2014) "Brasilien - gelobtes Land für Flüchtlinge?", http://www.dw.com/de/brasilien-gelobtes-land-f\%C3\%BCr-fl\%C3\%BCchtlinge/a17369497

Pressman R. S. (2011) "Engenharia de Software: uma abordagem profissional”. 7. ed. Nova York: Bookman.

Sommerville, I. (2007) "Engenharia de Software”. 8. ed. São Paulo: Pearson Addinson-Wesley.

Teixeira, P. (2009) "Direitos Humanos dos Refugiados", In: Dir., Pol. Publ. e Mundial., v. 6, p. 15-34.

Vermelho. (2015) "Pedido de refúgio de sírios no Brasil aumentou 9.000\% em 4 anos", http://www.vermelho.org.br/noticia/260591-10. 